\title{
TECNOLOGIA E DESAFIOS DA EDUCAÇÃO BRASILEIRA CONTEMPORÂNEA
}

\author{
TECHNOLOGY AND CHALLENGES OF CONTEMPORARY BRAZILIAN EDUCATION
}

Roberta Maria Lobo da Silva ${ }^{1}$

Resumo Este artigo busca apresentar uma discussão conceitual sobre tecnologia, tendo como horizonte um projeto de educação centrado na liberdade humana. É um resultado parcial da linha de pesquisa Educação, Cultura e Tecnologia/Grupo de Pesquisa Teoria Crítica e Educação, da Universidade Federal Rural do Rio de Janeiro/Conselho Nacional de Desenvolvimento Científico e Tecnológico (UFRRJ/CNPq), que tem como objetivo desenvolver projetos de pesquisa sobre a relação existente entre educação, cultura e tecnologia a fim de discutir as mudanças do estatuto epistemológico da educação nos séculos XX e XXI. A referência teórica está centrada no pensamento de Herbert Marcuse, em especial em seus conceitos de racionalidade crítica e racionalidade tecnológica. À luz destes conceitos, apresentaremos os desafios da educação contemporânea brasileira diante de uma realidade de imensos territórios segregados espacial e socialmente, bem como do apelo de uma sociedade do espetáculo embrutecedora dos sentidos e intensificadora do fetiche da mercadoria. Partindo deste contexto, apresentaremos as possibilidades da educação preparar os jovens para a participação ativa no mundo da cultura através da exploração da imaginação histórica e estética, tendo como referência a produção audiovisual.

Palavras-chave tecnologia; educação; produção audiovisual.
Abstract This article presents a conceptual discussion on technology, as it relates to an educational project centered on liberty. It is a partial result of the Line of Research on Education, Culture and Technology/Critical Theory and Education Research Group, at the Federal Rural University of Rio de Janeiro/National Council for Scientific and Technological Development (UFRRJ/CNPq). The objective of this research group is to develop research projects on the relationship between education, culture and technology, with a view to discussing the changes in the epistemological status of education in the 20th and 21 st centuries. The theoretical reference centers on the work of Herbert Marcuse, particularly his concepts of critical rationality and technological rationality. In the light of these concepts, we will present the challenges of Brazilian contemporary education, faced with a reality of immense territories that are spatially and socially segregated, and of the appeal of a society of spectacle that desensitizes the person and intensifies the commercial object as fetish. In this context we will present the possibilities of education to prepare young people for an active participation in the world of culture through the exploration of historical and aesthetic imagination, with a reference in audiovisual production.

Keywords technology; education; audiovisual production. 


\title{
Introdução
}

\author{
"Como podem as pessoas que tenham sido \\ objeto de dominação eficaz e produtivo criar \\ elas próprias as condições de liberdade?" \\ (Marcuse, 1967, p. 27).
}

Como no mundo atual engendrar processos de valorização do homem, tendo em vista o domínio da eficiência da racionalidade tecnológica e da epidemia da guerra, que se alastra com velocidade no cotidiano dos humanos do século XXI? Quantos deles restarão num decênio? De que qualidades se abstraem?

Os processos de valoração do homem derivam dos processos de organização social e de produção cultural. A totalidade da práxis, divisão do trabalho, linguagem, sociabilidade, ideologia, atividade criadora, subjetividade livre e alienada, conforma a matéria da vida em sua realidade histórica. A intensa dialética da cultura, transvestida em civilização e regressão, irrompe cadeias de fatos seculares no céu abismal da história, manifestam-se a razão autêntica, a razão auto-referente, a razão totalitária e a razão mortífera. No subterrâneo, como velha toupeira, por vezes com sabedoria, por outras com ingenuidade, insiste a razão emancipadora, subversiva e criadora.

Como enfrentar, os desafios do século XXI, no que tange ao fortalecimento de processos de valorização do humano num país periférico e numa sociedade decadente, como a sociedade brasileira, empobrecida culturalmente e espoliada materialmente? Como fortalecer processos pedagógicos que fomentem a autonomia e a crítica social dos jovens das classes populares subjugados à condição instrumental de massa?

Desde a segunda metade do século XX, a sociedade industrial moderna foi aperfeiçoando seus mecanismos de contenção da transformação social, descaracterizando lutas históricas pela democratização da riqueza, da cultura e da educação. Ao reduzir o ideal da democracia ao corriqueiro, operacional e ilusório aumento do poder de consumir mercadorias e de ser consumido como tal, o século XX fortaleceu o domínio das coisas sobre os homens, intensificando um processo de valorização das coisas que torna o humano descartável, principalmente quando este não possui poder de compra.

Deste modo, objetivamente são relegados ao limbo da humanidade milhões e milhões de pessoas, ainda que subjetivamente estejam mergulhados na contemplação passiva da sociedade do espetáculo. Tomamos como referência o conceito de sociedade do espetáculo elaborado por Guy Debord, que se define pelo auge do fetichismo da mercadoria, atingido após 
a segunda metade do século XX. A transformação das relações humanas em relações entre coisas se metamorfoseia em relação entre imagens, assim a degradação da vida social do ser para o ter se prolonga na redução ao parecer.

“Debord explica que o espetáculo é uma forma de sociedade em que a vida real é pobre e fragmentária, e os indivíduos são obrigados a contemplar e a consumir passivamente as imagens de tudo o que lhes falta em sua existência real" (Jappe, 1995, p. 3).

Retomaremos o tema adiante.

Segundo Marcuse, a aceitação de uma sociedade irracional, pautada pela "produtividade crescente e pela destruição crescente, pela rendição do pensamento, das esperanças e do temor às decisões dos poderes existentes" (Marcuse, 1967, p. 17), reprime a necessidade de uma alteração qualitativa do modo de vida, a necessidade de recusa e de subversão, utilizando a eficiente produção e consumo intenso de mercadorias, bem como a conquista científica do homem e da natureza.

O século XX materializa a dialética da contenção e da explosão social sob a lógica de uma racionalidade tecnológica, que aniquila a autonomia do indivíduo através de uma integração domesticada. Tal integração se dá através de mecanismos de controle social que consolidam a coerção e o consenso no trabalho, no amor, na escola, no cinema e na dor. O século XXI anuncia o contexto da ignorância massificada, da militarização dos territórios segregados e da derrota da esquerda social. Que possibilidades a educação contemporânea pode abrir para a liberdade humana, como elaborar, esteticamente, politicamente, filosoficamente as cesuras históricas impostas aos herdeiros da luta pela razão emancipadora?

\section{Situando historicamente a geração de Marcuse (1898-1979)}

As décadas de 1920, 1930 e 1940 abriram caminhos para uma reflexão dialética sobre as derrotas da revolução socialista na Europa, as vitórias do fascismo e do stalinismo, antecipando análises sobre as tendências da sociedade moderna com seu capitalismo avançado, apontando e projetando a necessidade emergencial de uma reatualização da teoria marxista e de sua práxis política posta pela negação da liberdade materializada pelo terror instaurado no século XX.

Intelectuais influenciados pela cultura clássica alemã e pela cultura modernista, como Lukács, Brecht, Benjamin, Marcuse, Adorno, que vivenciaram o exílio a partir de 1933, produziram reflexões no campo da teoria 
do conhecimento, da estética, da crítica historiográfica e da teoria social, buscando não apenas compreender os mecanismos objetivos e subjetivos do domínio da sociedade de massas e do imperativo tecnológico, mas também apontar as potencialidades geradas por esta sociedade no que tange à incansável luta pela emancipação humana. Neste período, surgem as bases do debate sobre a arte e a técnica que envolveu os cubistas e os construtivistas russos das primeiras décadas do século $\mathrm{XX}$, debate que fundamentou o rico diálogo estabelecido entre Brecht e Benjamin na década de 1930.

Os destinos destes intelectuais foram bem distintos, uns mais complacentes, outros mais trágicos. Lukács, exilado na Rússia soviética, mantém a disciplina de subjugar-se ao consenso forçado. Brecht escolhe a Dinamarca, terreno neutro para observações de terras longínquas, bem como para experimentações de uma estética da produção com ilusões ainda permitidas. Benjamin, apesar da solidariedade do amigo Brecht, que o acolhe em 1934, 1936 e 1938, isola-se cada vez mais e embrenha-se no labirinto sem saída da barbárie fascista, suicida-se. Marcuse e Adorno seguem para os EUA, buscando refúgio na tentativa de Horkheimer institucionalizar em país estrangeiro o Instituto de Pesquisa Social, fundado em Frankfurt na década de 1920.

Entre os anos de 1942 e 1950, Marcuse atuará diretamente no Departamento de Estado dos EUA, produzindo análises e relatórios sobre a Alemanha. Em 1954, com a onda de caça aos comunistas, instaurada pelo senador McCarthy, Marcuse se refugia numa universidade provinciana em Brandeis, época de produção intensa no exercício da atividade do esquecimento. Dez anos depois, em 1964, lança o livro O homem unidimensional - ensaios sobre a ideologia da sociedade industrial avançada, o que lhe custará a demissão, assim como uma popularidade impressionante. Nos anos seguintes, vai atuar na Universidade de Berkeley, também numa situação delicada devido à defesa das revoltas estudantis nos EUA, na França, na Alemanha, Argentina, México, Brasil etc., contra a sociedade do bem-estar social, da cidadania adestrada, do consumo, das guerras e ditaduras.

Marcuse passa a compartilhar lugar de referência nas revoltas de 1968 ao lado de Marx e Mao, reforçando não somente seu aspecto político, mas também seu aspecto cultural, de contracultura. É ameaçado pela Ku Klux Kan e, com o apoio do então governador da Califórnia, Ronald Reagan, foi novamente demitido. Finalmente, fixa-se na Universidade de San Diego, Califórnia, ministrando as cadeiras de Filosofia e Ciência Política até o final da década de 1970. A coerência teórica e política de Marcuse já se faziam presentes desde a primeira década do século $\mathrm{XX}$, quando aposta na revolução alemã de 1918-1919. Marcuse foi soldado na Primeira Guerra Mundial e, mesmo filiado ao Partido Social Democrata Alemão, participa de 
conselhos de operários e soldados e luta pela revolução socialista ao lado dos spartakistas Rosa Luxemburgo e Karl Liebknecht.

\section{Dialética da racionalidade crítica e da racionalidade tecnológica}

Partimos da hipótese de que as análises de Marcuse sobre a tecnologia na sociedade contemporânea, sobre a arte e o amor como potencialidades do ideal de liberdade podem apontar para um programa de educação para a emancipação humana.

Neste artigo, iremos nos restringir às relações existentes entre a racionalidade tecnológica e crítica, tecnologia e técnicas de produção, entre domesticação e potencialidade histórica da liberdade apontadas por Marcuse, buscando abrir questões para a reflexão teórica e a ação prática da educação contemporânea.

Em 1941, Marcuse escreve Algumas implicações sociais da tecnologia moderna, iniciando uma reflexão que une formação e declínio da individualidade burguesa, totalitarismo e racionalidade tecnológica.

Marcuse descreve a função histórica da racionalidade crítica fomentada pelas revoluções burguesas, bem como suas metamorfoses na sociedade da racionalidade tecnológica. Deste modo, realiza uma dialética entre racionalidade crítica e racionalidade tecnológica, herdando questões da autonomia de Kant e da heteronomia do senhor e do escravo de Hegel, diferenciando-se numa outra síntese marcada pelas contradições do fascismo e do stalinismo. A crença na individualidade livre e a crítica da individualidade submissa que atravessam estes fenômenos históricos permitem Marcuse ressaltar potencialidades da tecnologia como elemento de criação e de liberdade, não sendo, portanto, tão-somente o processo social, as invenções humanas e os instrumentos que organiza, numa totalidade opressora, o sistema de dominação do capital.

Marcuse, formado pela cultura filosófica alemã, mantém vivo o desafio de dar significado à razão humana. Também nos anos de 1940, Horkheimer e Adorno estão enfrentando os dilemas de uma dialética do esclarecimento, traçando os domínios de uma racionalidade instrumental que alia ciência e técnica com a função de subjugar a natureza e os homens à lógica da produção de mercadorias.

A racionalidade crítica, oriunda da sociedade burguesa liberal, funda-se na autonomia, na liberdade de pensamento, na dinâmica do indivíduo de superar as idéias e valores impostos pela sociedade, afirmando seu interesse, rejeitando tudo que não fosse justificado e elaborado pela atividade racional. Deste modo, no seio da sociedade liberal e de sua esfera da livre concorrência, a crítica era o instrumento principal no processo de 
constituição da racionalidade individualista, também marcada pela conduta social do trabalho: “Os feitos tangíveis do indivíduo que transformava seus produtos e ações em parte das necessidades da sociedade eram as marcas de sua individualidade" (Marcuse, 1999, p. 76).

A superação da sociedade burguesa liberal se estabelece na virada do século XIX para o século XX, com a dinâmica de uma sociedade de massas e de um capitalismo monopolista, onde a separação sujeito e objeto se consolida no domínio da técnica sobre a natureza e sobre os instintos humanos.

Para Marcuse, o capitalismo monopolista elimina o sujeito econômico livre com a instauração de um alto nível de mecanização e padronização do processo de produção de mercadorias. Sendo assim, o processo de produção de mercadorias que possibilitou historicamente o surgimento da racionalidade crítica do indivíduo burguês, ao atingir uma certa maturidade e alcançar poder tecnológico concentra cada vez mais poder econômico (extração de matérias-primas, equipamentos, processos de circulação e de distribuição dos produtos), impondo novos padrões de individualidade e racionalidade $\mathrm{Se}$, antes, o papel do indivíduo era questionar tudo que não fosse elaborado por sua atividade livre racional, colocando-se, quando necessário, contra a sociedade, agora o papel do indivíduo é submeter-se à dinâmica criada pelo aparato técnico-industrial (mecanismos, dispositivos, organizações econômicas, instituições sociais e políticas) do capitalismo monopolista. A racionalidade tecnológica, portanto, é a sujeição do indivíduo às necessidades do aparato.

A tecnologia do século XX produz novas formas de sociedade e de cultura, alterando substancialmente os processos de valorização dos indivíduos, bem como os processos de produção da riqueza e de organização social. O fundamento da vida social como realidade posta está na manutenção e reprodução do sistema de produção de mercadorias: do comezinho do cotidiano à resignação, a subjetividade humana vai se abstraindo de si, de todo conteúdo humano, automatizando-se como resposta direta às exigências de identidade posta pelo capital. Marcuse define como nova factualidade, a materialidade de uma sociedade que se reproduz no seu cotidiano e nas grandes questões através de uma racionalidade que determina uma nova objetivação social, combinando, inclusive, indústria, comércio e lazer.

“É um aparato racional, combinando a máxima eficiência com a máxima conveniência, economizando tempo e energia, eliminando o desperdício, adaptando todos os meios a um fim, antecipando as conseqüências, sustentando a calculabilidade e a segurança" (Marcuse, 1999, p. 80).

Se tudo é tão conveniente e conivente, para que a liberdade de escolha? Aqui reside um dos princípios da derrota da revolução social. O mundo 
torna-se um aparato ultra-eficiente para a reprodução do sujeito automático do capital, transformando os instintos, as ações e os pensamentos humanos.

“A máquina adorada não é mais matéria morta, mas se torna algo semelhante a um ser humano. E devolve ao homem o que ela possui: a vida do aparato social ao qual pertence. O comportamento humano se reveste da racionalidade do processo da máquina, e esta racionalidade tem um conteúdo social definido. O processo da máquina opera de acordo com as leis da ciência física, mas da mesma forma opera com as leis da produção de massa" (Marcuse, 1999, p. 81).

Determinado por esta nova factualidade, a racionalidade crítica se suicida, mantendo-se sob uma consciência inconsciente de adoração do aparato. $\mathrm{O}$ indivíduo se comporta com tamanha racionalidade e devoção frente ao seu trabalho e ao seu cotidiano, garantindo os fundamentos da racionalidade tecnológica. Este processo de racionalização não se restringiu ao mundo das fábricas, dos laboratórios e das lojas, pelo contrário, expandiu-se intensivamente pelo mundo das escolas, dos escritórios, dos poderes legislativos e do lazer.

"A razão encontrou o seu túmulo no sistema de controle, produção e consumo padronizados. Ali ela reina através das leis e mecanismos da racionalidade tecnológica, que asseguram a eficiência, a eficácia e coerência do sistema". (Marcuse, 1999, p. 84).

Mesmo apresentando como derrota a forma como foi materializada os princípios da racionalidade crítica, Marcuse (1999) trata de apresentar uma dialética entre o conjunto de valores que sustentam a racionalidade crítica e o conjunto de valores que sustentam a racionalidade tecnológica, mostrando como eles se movem contraditoriamente e complementarmente e produzem metamorfoses diante de determinados contextos históricos, quando o conjunto de valores críticos se tornam valores tecnológicos e/ou vice-versa. A racionalização da padronização arranca valores críticos de seu contexto de origem, absorvendo-os para seu contexto publicitário, de valorização do capital, sendo pautados seja pelo mundo público/estatal ou privado.

Marcuse aponta duas condições sociais que fortaleceram a impotência do pensamento crítico: o ajuste massivo dos comportamentos individuais através de métodos de autocontrole e autodisciplina, de modo a internalizar a coerção e a autoridade do aparato. "Homens, seguindo sua própria razão, seguem aqueles que fazem uso lucrativo da razão" (Marcuse, 1999, p. 86). Outra condição da impotência do pensamento crítico foi a incorporação da oposição ao aparato, sem perder o título de oposição. Segundo Marcuse, 
ocorre uma mudança de função do conjunto de valores críticos promovidos pelo trabalho a partir da realidade concreta de incorporação do movimento operário ao aparato. Podendo, devido ao grau elevado de automação e de produtividade do trabalho, abolir o trabalho enquanto esfera das necessidades socialmente úteis, por que então o movimento operário não fortalece a luta pela socialização da riqueza em vez de se restringir aos processos de negociação de aumento de salários e participação nos lucros com o Estado e o grande capital? O movimento operário nega a necessidade da racionalidade crítica para a manutenção de seu peso social e político, as "idéias como liberdade, indústria produtiva, economia planejada, satisfações de necessidades vêem-se fundidas com os interesses de controle e competição" (Marcuse, 1999, p. 87-88).

A oposição consentida, a sedução para a entrada no reino do consumo ou a permissão mesmo que subordinada às esferas de poder e de prestígio abrem caminho para pactos sociais entre capital e trabalho, fazendo surgir no cenário político uma esquerda reprodutora da racionalidade tecnológica. Uma recordação da realidade histórica vivida nos anos de 1990 pelos países do leste europeu e pelos países da América Latina, que, sob uma democracia flácida, instauram a cartilha do neoliberalismo: ajustes, eficiência, flexibilidade.

Marcuse observava, já nos anos de 1940, o fortalecimento da racionalidade tecnológica na crescente hierarquização do aparato técnico-industrial (com suas burocracias públicas e privadas), bem como na diluição do indivíduo em massa, sendo no conjunto a forma madura da racionalidade individualista e ao mesmo tempo sua negação. Vale a pena ressaltar que seus olhos estão voltados para o fenômeno histórico do totalitarismo, manifestado tanto pelo nazismo quanto pelo stalinismo. No entanto, a continuidade de suas reflexões apontará formas totalitárias para além destes fenômenos históricos. Segundo Marcuse, a sociedade industrial contemporânea é totalitária, não por uma coordenação política terrorista e sim por uma "coordenação técnico-econômica não terrorista que opera através da manipulação das necessidades por interesses adquiridos" (Marcuse, 1967, p. 25).

Com a consolidação da racionalidade tecnológica, ou seja, de uma individualidade submissa ao aparato técnico-industrial-burocrático, a autonomia do indivíduo torna-se assunto privado, o indivíduo se retira, cai no isolamento e na concepção de que deve resolver sozinho o seu problema, ou seja, em última instância, o problema e sua resolução é individual. O isolamento aparece como realização de uma liberdade que jamais irá interpelar criticamente o conjunto das relações sociais nas quais o indivíduo está inserido, negando assim sua capacidade de revoltar-se. O indivíduo se mantém alheio, gozando ou não de uma independência privada. 
Diante desta realidade torna-se necessário rever a dialética da liberdade, ou seja, rever a concepção de liberdade com base na superação da autonomia burguesa, na construção da autonomia livre da coerção e da forma mercadoria. Assim nos diz Marcuse:

\begin{abstract}
"Liberdade econômica significaria liberdade de economia - de ser controlado pelas forças e relações econômicas; liberdade de luta cotidiana pela existência, de ganhar a vida. Liberdade política significaria a libertação do indivíduo da política sobre a qual ele não tem controle eficaz algum. Do mesmo modo, liberdade intelectual significaria restauração do pensamento individual, ora absorvido pela comunicação e doutrinação de massa, abolição da opinião pública juntamente com seus forjadores" (Marcuse, 1967, p. 26).
\end{abstract}

Na verdade, o desafio é tornar consciente os mecanismos de controle social instaurados pela racionalidade tecnológica e subverter a realidade de uma liberdade transformada em instrumento de dominação, como a liberdade para a produção e consumo do desperdício, a liberdade de escolha entre a variedade de mercadorias e serviços ou a liberdade de escolha dos senhores. Em todas estas expressões de liberdade não foram abolidas as condições de trabalho que negam a vida, não foram abolidas as condições de perpetuação da dialética do senhor e do escravo, tampouco se pode afirmar que a reprodução espontânea do indivíduo das necessidades impostas implica autonomia, ao contrário, somente reafirma a eficácia de tais controles, uma consciência inconsciente que reproduz o sujeito automático do capital.

Tal consciência inconsciente é própria do indivíduo metamorfoseado em massa. Para Marcuse, a massa é uma associação de indivíduos reduzidos à padronização da individualidade abstrata. "Como membro da multidão, o homem se tornou o sujeito padronizado da autopreservação bruta (...) A multidão é assim a antítese da 'comunidade' e a realização pervertida da individualidade" (Marcuse, 1999, p. 89). Os impulsos agressivos, além de um estado de espírito anterior, se desenvolvem diante das exigências da escassez e da frustração, reafirmando um sujeito atomizado, desligado de tudo que transcende seus interesses e impulsos egoístas. É inegável a importância das massas para os pilares da racionalidade tecnológica, bem como sua transformação em força conservadora para a manutenção da existência do homem (sentimentos, pensamentos e interesses) como instrumentalidade do aparato. A massa como união de indivíduos instrumentalizados pelo aparato faz parte do cotidiano do processo de controle social, moldando o indivíduo para a recusa da liberdade e da resistência ao aparato, tornando-se uma unidade maleável e adaptável associado à massa. 
Neste iniciar de século, com uma sociedade de massas plenamente adequada à funcionalidade do capital e pautada pelos desígnios da indústria cultural, quais as possibilidades reais de uma crítica à racionalidade tecnológica que ponha no horizonte uma dialética da liberdade instauradora da vida como um fim em si mesmo, onde o indivíduo se reconheça como tal, sem os aprisionamentos impostos pela condição de massa e pela forma mercadoria?

\section{Dialética da tecnologia e da técnica}

Compreender a dialética da tecnologia e da técnica em Marcuse possui um papel fundamental no nosso interesse de articular tecnologia e educação. Negar a postura do senso comum ideologizado e dicotômico que reforça uma visão da tecnologia como algo genuinamente grandioso para a humanidade, ou como algo destruidor, é pressuposto para uma análise mais coerente sobre os destinos ainda possíveis da sociedade contemporânea. O estudo crítico da tecnologia no século XXI pode ajudar a potencializar a dimensão cognitiva da tecnologia, bem como a crítica da sociedade do trabalho, retomando releituras de Marx que ressaltam a relação entre automação progressiva e tempo livre como condição para a realização da liberdade humana².

Marcuse aponta para uma dialética entre técnica e tecnologia, abrindo caminho para demarcar as potencialidades das técnicas de produção, bem como para ampliar o conceito de tecnologia.

Tecnologia deve ser compreendida

"como modo de produção, como totalidade dos instrumentos, dos dispositivos e invenções que caracterizam a era da máquina, é ao mesmo tempo uma forma de organizar e perpetuar (ou modificar) as relações sociais, uma manifestação do pensamento e dos padrões de comportamento dominantes, um instrumento de controle e de dominação." (Marcuse, 1999, p.73).

Sendo processo social, a tecnologia está fora do homem? Ou, onde está o homem no aparato técnico da indústria, dos transportes e da comunicação? "Os indivíduos são parte integral e fator da tecnologia, pois inventam e mantêm a maquinaria, bem como fazem parte de grupos sociais que dirigem a aplicação e utilização da tecnologia" (Marcuse, 1999, p. 74).

Se, para Marcuse, a tecnologia fundamenta e sustenta o aparato de produção e de controle social das sociedades do capitalismo monopolista, as técnicas de produção encerram em si outras possibilidades, visto que podem "promover tanto o autoritarismo quanto a liberdade, tanto a escassez 
quanto a abundância, tanto o aumento quanto a abolição do trabalho árduo" (Marcuse, 1999, p. 74). O avanço das técnicas de produção e dos usos dos instrumentos pode liberar forças no processo social e nos indivíduos, tornando-os capazes de aniquilar a forma histórica particular em que a técnica é utilizada como um aparato que perpetua a escassez, a competição e a submissão dos indivíduos.

Um outro elemento apontado por Marcuse, no que diz respeito às potencialidades das técnicas de produção, está na possibilidade da democratização das funções em todos os ramos do trabalho e da administração, tornando tanto a mecanização quanto a padronização condição para a livre realização humana, não sendo apenas condição de satisfação das necessidades de produção e expansão do valor de troca.

Existe uma convergência entre racionalidade crítica e tecnológica: o processo tecnológico implica a democratização das funções. O sistema de produção e de distribuição racionalizado é cada vez menos baseado em distinções essenciais de aptidão e compreensão e cada vez mais no poder herdado e num treinamento vocacional onde todos poderiam estar sujeitos. O abismo entre população subordinada e elaboradores dos projetos de racionalização (planejamento da produção, invenções que aceleram o progresso tecnológico) "se mantém mais pela divisão do poder do que pela divisão do trabalho" (Marcuse, 1999, p. 92).

Marcuse, numa releitura de Weber, sustenta que a tecnologia cria burocracias privadas, partidárias e públicas com a finalidade de promover o controle da massa, indo contra a tendência acima descrita de democratização das funções. A democratização técnica das funções é neutralizada por sua atomização, e a burocracia surge como o órgão que garante a ordem racional destas funções, potencializando a racionalidade da submissão, "pois quanto mais as funções individuais são divididas, fixadas, sincronizadas de acordo com padrões objetivos e impessoais, tanto menos é razoável para o indivíduo recuar ou resistir" (Marcuse, 1999, p. 94). No entanto, Marcuse também afirma que as burocracias públicas podem ser potenciais de democratização caso desenvolvam ações no sentido de impedir a invasão do bem-estar geral pelos interesses privados, conservando recursos humanos e materiais. Assim sendo, a sociedade terá passado do estágio de burocratização hierárquica ao estágio de auto-administração técnica (Marcuse, 1999).

Na dialética apresentada por Marcuse, o progresso tecnológico, apesar de ter reduzido as ricas qualidades humanas através de uma estúpida abstração do seu conteúdo particular convertida em nova factualidade, pode sim apontar para novas formas de desenvolvimento humano.

“O progresso tecnológico possibilitaria diminuir o tempo e a energia gastos na produção das necessidades da vida, além de redução gradual da escassez. 
Abolição dos objetivos competitivos poderia permitir que o eu se desenvolvesse a partir de suas raízes naturais. Quanto menos tempo e energia o homem precisar gastar para manter a sua vida e a da sociedade, maior a possibilidade de ele poder 'individualizar' a esfera de sua realização humana. Para além do reino das necessidades, as diferenças essenciais entre os homens poderiam se expandir (...) sem estar preso à eficiência competitiva, o eu poderia crescer no reino da satisfação. O homem poderia encontrar consigo mesmo em suas paixões. Os objetos de seu desejo seriam tanto menos permutáveis quanto mais fossem moldados por seu livre eu" (Marcuse, 1999, p. 103).

O ser humano livre, agindo para além do reino da necessidade! Esta utopia tem como base relações humanas não coisificadas, ou seja, livre das determinações da lógica de produção de mercadorias, como a servidão voluntária do trabalho alienado, a ameaça da pobreza, do isolamento social e político. Sem negar a existência do conflito, do transitório e do contingente, os homens partiriam para produções qualitativamente novas sem determinações externas ou imposições da ordem do necessário, engendrando assim novas subjetividades conscientes de seu estar no mundo, liberadas pela atividade criadora, pela arte e pelo amor. Marcuse acredita que, mesmo sob o domínio da racionalidade tecnológica, o declínio da racionalidade crítica e o fracasso da racionalidade coletiva, ainda há possibilidades de novos processos de individualização com a utilização do progresso das técnicas de produção, ainda que tais processos sejam inerentemente transitórios e conflituosos.

\section{Desafios da educação brasileira contemporânea}

"Quem é que tá botando dinamite

Na cabeça do século? Quem é que tá botando tanto piolho

Na cabeça do século?

Quem é que tá botando tanto grilo

$\mathrm{Na}$ cabeça do século?

Quem é que arranja um travesseiro Para cabeça do século?"

(Trecho da música Defeito de fabricação, de Tom Zé, 1998).

O século XXI materializa a sociedade tecnológica, com sua automação progressiva e sua tolerância repressiva ${ }^{3}$, concentração de poder político e econômico, política de extermínio e reverência à indústria bélica, apologia 
da potencialidade tecnológica das forças de destruição. O voltar-se para a dinamite que encurtou o futuro e negou a liberdade deve ser o ponto de partida para a reflexão teórica e prática da Educação.

A realidade posta exprime-se na rejeição de novos modelos de racionalidade, de novos sentidos para a arte e para a atividade humana criadora. Exprime-se, sobretudo, pelo seu caráter excludente. A razão não trouxe a autonomia, ao contrário, estimulou a criação de formas de controle social, expandindo e intensificando a produtividade do trabalho a custo da expansão e intensificação da regressão à barbárie.

Os educadores brasileiros possuem como primeiro grande desafio da sua práxis pedagógica reconhecer e estranhar o grito de Adorno no final da Segunda Guerra Mundial: O que a educação pode fazer para que Auschiwitz não se repita?

Auschiwitz se repetiu várias vezes, na Guerra Fria, nas ditaduras latino-americanas, na época das guerras preventivas, como as guerras no Oriente Médio, e também se repete no cotidiano das periferias das grandes cidades do Brasil como guerra civil. O extermínio torna-se política de segurança nacional, com planificação burocrática e a execução em escala industrial. O Estado atua sistematicamente nos territórios segregados socialmente, reprimindo, matando os filhos da classe desfigurada e contida nas fronteiras enrijecidas da superexploração do trabalho, do sistema carcerário e das permissões de circulação no interior destes territórios. Os jornais impressos e televisivos estão marcados pelas catástrofes sociais que banalizam, dia a dia, a existência humana e o horror instaurado.

\section{Educação e guerra civil}

"La libertad es un fantasma. Esto lo he pensado seriamente y lo creo desde siempre. Es un fantasma de niebla. El hombre lo persigue, cree atraparlo, y solo le queda un poco de niebla entre las manos"

(Luis Buñuel, O fantasma da liberdade, 1974).

Sem negar o fantasma da liberdade, devem os educadores questionar a relação entre educação e guerra civil na contemporaneidade?

A generalização da segregação espacial é uma condição da guerra civil instaurada. Existem na cidade do Rio de Janeiro 700 favelas, na Baixada Fluminense habitam mais de 3,4 milhões de pessoas. No mundo existem mais de 200 mil favelas com mais de um bilhão de habitantes. Em 2005, já havia no mundo um bilhão de favelados. 
“Os favelados, embora sejam apenas $6 \%$ da população urbana dos países desenvolvidos, constituem espantosos $78,2 \%$ da população urbana dos países menos desenvolvidos; isso corresponde a pelo menos um terço da população urbana global" (Davis, 2006, p. 33-34)4.

Uma parte da população urbana brasileira, domesticada nas favelas e nas periferias, domesticada nas longas horas desconfortáveis do trajeto casatrabalho, nas longas horas em frente à TV, vive a ilusão da busca de um centro que lhe permita algum consumo, mesmo que de baixa qualidade. Os territórios segregados acolhem a massa aligeirada, causalidade posta no árido quadro social brasileiro: 12 milhões de desempregados; 13 milhões na economia informal (25\% do PEA e $6 \%$ do PIB); 34 milhões sem carteira assinada; 5 milhões de trabalhadores agenciados por 'CoperGatos'; 11 milhões de famílias vinculadas ao Programa Bolsa Família (Dieese, 2006).

Outra parte da população dos territórios segregados tornou-se descartável, sitiada entre duas possibilidades 5 degradantes: a primeira é de subjugar-se a uma informalidade pérfida que reforça o desumano, a loucura e a morte. Milhares de homens, mulheres e crianças se tornam catadores de lixo, vivem de papelões, latas, restos, moram em buracos pouco iluminados e sem água, massificam-se nas beiras das rodovias e linhas expressas, oferecendo seus serviços ou mercadorias, trabalhando horas, sem garantia alguma de dar conta do mínimo requerido para manter sua luta pela existência. Sobrevivem com uma alimentação precária, sofrem enfermidades crônicas, tornam factual o esgarçamento das relações sociais e a agressividade no convívio.

No rastro de uma estatística crua e sem valor, parte desta população enfrenta a segunda possibilidade: a de sujeitar-se à vala comum, ao extermínio à luz do dia ou na frieza da noite empoeirada.

Existe hoje no Brasil uma estampada guerra civil, marcada pela segregação de territórios e pela frieza social que naturalizam a relação violenta com as classes subalternas. Esta reação violenta tem como função garantir a superexploração própria da sociedade de classes e do regime de concorrência mundial. Um importante aspecto desta segregação de territórios é sua funcionalidade ideológica, pois legitima a parte eleita da população que irá usufruir os territórios com condições ideais de existência, eleita a partir de seus méritos e capacidades, bem como a parte descartada da população, moralmente fraca e culpada pela ineficiência econômica que os impede de se elevar ao território ideal. Na cidade segregada, os favelados que são os incapazes, as bestas, os sem-valor, se transformam em bandidos que devem ser reprimidos e mortos, de modo a garantir a ordem para a classe dos eleitos (Menegat, 2006). 
“Cantos do Pelotão da elite da Polícia Militar do Rio de Janeiro: 'O interrogatório é muito fácil de fazer, pega o favelado e dá porrada até doer. O interrogatório é muito fácil de acabar, pega o bandido e dá porrada até matar. $\mathrm{O}$ bandido favelado não se varre com vassoura, se varre com granada, fuzil e metralhadora."' (Menegat, 2006, p. 108).

Esta guerra civil também se manifesta na informalidade, na migração, na delinqüência, na mendicância. Os jovens são os mais atingidos. Segundo os dados do Instituto Brasileiro de Geografia e Estatística (2000), 48 milhões de jovens (15 a 29 anos) representam $28 \%$ da população brasileira, sendo que $40 \%$ destes jovens vivem nas periferias urbanas com famílias sem rendimento ou com rendimento até meio salário mínimo. A realidade da juventude favelada e de periferia hoje está marcada pelo extermínio, violência policial, desemprego, baixa escolaridade, drogas, ONG's e igrejas pentecostais. O Rio de Janeiro é a cidade brasileira com maior número absoluto de assassinatos de jovens de 15 a 24 anos, segundo o Mapa da Violência dos Municípios Brasileiros. Em 2006, foram registradas 879 mortes nessa faixa etária nesta cidade. Somados os assassinatos de 1996 a 2006, o total é de 186.921 vítimas jovens no país (Waiselfisz, 2007). A situação concreta dos jovens das periferias e das favelas impõe o sentimento generalizado de desencanto, temor, desconfiança, intolerância e agressão sobre a constituição de suas subjetividades.

Aqui vale a pena situarmos a dialética da liberdade e da agressão na sociedade tecnológica, visto que atravessa toda a sociedade e não apenas os jovens. Segundo Marcuse, as novas necessidades e satisfações, as novas liberdades oferecidas pela sociedade tecnológica operam contra a autêntica liberdade do homem, jogando as faculdades físicas e mentais, as energias instintivas do homem contra ele próprio, resultando numa profunda frustração e numa ativação da agressividade. Ainda que a energia agressiva tenha sido necessária para o progresso da civilização, Marcuse aponta para uma situação onde a ativação da energia agressiva torna-se mortalmente des trutiva. A sociedade tecnológica alia agressão instintiva e agressão política:

“(...) a relação entre as tendências expansionistas da sociedade opulenta, neocolonialismo, neoimperialismo, por um lado, e a agressão normal, por outro. A sociedade opulenta deve ativar e mobilizar a agressividade numa escala ainda maior" (Marcuse, 1968, p. 3).

A educação como teoria crítica da sociedade não pode se furtar destas questões se pretende de fato tornar o futuro grávido de projetos de emancipação. É a partir da negatividade que nos aproximamos do real. Como 
realizar processos de valoração humana sob a realidade fraturada em ilhas de excelências em contraposição às largas extensões de pobreza, territórios em guerra civil da cidade punitiva que não devem atravessar as fronteiras da cidade cidadã, consumidora de produtos e serviços?

Renova-se na contemporaneidade um terrorismo de Estado que contém milhões de pessoas, que integra pela organização do trabalho cada vez mais precário e descarta os dejetos que circulam sem finalidade. Para Arantes, desde o tempo do 18 Brumário, o poder político burguês utiliza o seu grande achado institucional: a codificação da exceção na norma legal.

“Marx fez assim a crônica desse nascimento conjunto da exceção e da regra, dando a entender, à vista do roteiro que culmina num golpe providencial destinado a livrar de uma vez por todas a sociedade burguesa da preocupação de governar a si mesma, que o Estado de direito dos sonhos de seus demiurgos estaria condenado a viver sob um regime de exceção permanente. Isto é, normal. A própria quadratura do círculo. Dá para sentir o drama de nossos ancestrais: como era preciso defender a sociedade contra os seus inimigos internos, uma outra semente lançada naqueles primeiros tempos de alta criatividade na guerra social, essa idéia de que é preciso defender a sociedade, nossos inventivos reformuladores do estado de sítio simplesmente introduziram a ditadura no ordenamento do Estado de direito. Daí o empenho grotesco, renovado a cada momento de transe, de legalizar a suspensão da legalidade" (Arantes, 2002, p. 2).

Além da naturalização de um estado de exceção, produzem-se extensiva e intensivamente a força da indústria cultural, a ratificação da subjetividade submissa, subjetividade encarcerada e pacificada. Alguns símbolos que impregnam a sociedade brasileira: Casas Bahia, Faustão, Igreja pentecostal, Bope, Caveirão, Créu. O consumo intensificado através do endividamento, a formação de valores através da mídia televisiva e de seu conteúdo banalizador, a resignação em massa e a bestialização do prazer. Todos são processos sociais reais engendrados pelo domínio da lógica de produção de mercadorias e que devem, em sua negatividade, ser compreendidos, desmontados, mesmo sob o curto tempo que se percorre sobre os fios de uma dinamite que está para explodir.

Reconhecer e estranhar a guerra civil como primeiro desafio a ser considerado pelos educadores brasileiros está aliado a uma segundo desafio. Entranhar-se no apelo imagético, espetacular do mundo atual. 


\section{Educação e produção audiovisual}

Temos que considerar que vivemos num mundo de superprodução, de excesso de imagens, como também de crise de imagens. Os programas de TV, os outdoors, as propagandas nos meios de transporte em geral, a internet. A imagem revela a realidade abstraída, estimula para consumo, padroniza o pensamento, com a intenção de eximir o espectador de interpretá-la e de negar sua capacidade de também produzi-la.

Retomamos aqui o conceito de sociedade do espetáculo, ressaltando sua importância para a compreensão do mundo atual, bem como para a elaboração de projetos de produção audiovisual por jovens e professores ${ }^{6}$.

Para Debord, o espetáculo não pode ser compreendido como um abuso do mundo visível, produto das técnicas de produção e difusão massiva das imagens; o espetáculo deve ser compreendido como uma relação social entre indivíduos, mediado por imagens escolhidas pelos que dominam a lógica de produção de mercadorias; deve ser compreendido como uma totalidade social concreta. Debord retoma Marx quando fundamenta o conceito da sociedade do espetáculo como um estágio avançado da sociedade produtora de mercadorias, aprofundando a análise do fetichismo da mercadoria, reconstruindo-a historicamente a partir da segunda metade do século XX (Jappe, 2003).

Se a sociedade contemporânea é uma imensa acumulação de espetáculos, e se esta acumulação se refere ao estágio avançado do fetichismo da mercadoria, trata-se, portanto, de um alto nível de abstração que reatualiza o fundamento cristalizado do trabalho abstrato: a abstração da qualidade particular em função da quantidade, da quantificação e expansão do valor, o que engendra a abstração da totalidade social pelos indivíduos. Ou seja, instaura-se a abstração do processo social, da relação direta entre os indivíduos em função da dupla realização da mercadoria como valor de uso e de troca, reduzindo-o a uma banal e naturalizada relação de compra e venda. A individualidade abstrai-se da humanidade através de relações fetichistas, dotando as coisas, objetos, técnicas, imagens de poderes sobre-humanos. O fetichismo como fenômeno histórico-social torna-se modelo de subjetivação e objetivação.

“O espetáculo com a sua redução do mundo a um mero parecer, a imagem, não é, portanto, outra coisa senão, como disse o próprio Debord, uma posterior etapa no processo secular do tornar-se abstrato do mundo, iniciado no Renascimento e continuado com cada vez mais força desde o final do século XVIII" (Jappe, 2003, p. 23). 
No que tange à educação do século XXI: no auge do fethicismo da mercadoria e da imensa acumulação de espetáculos, como produzir imagens que subvertam a educação implícita no processo de abstração? Como produzir imagens que se lançam sobre o conteúdo social e humano do mundo em sua densidade histórico-concreta? Não é apenas educar o olhar, mas elaborar este olhar, projetá-lo para contradizer, expor, rejeitar, tornar desconfortável e repugnante a sociedade do espetáculo. Educar para subverter a aceitação passiva do espetáculo, que restringe cada vez mais o raio das possibilidades humanas, reduzindo tudo ao mesmo, ao semelhante, ao padronizado em função da legitimação de um pensamento único e violentador, que prima pela mercantilização intensiva e extensiva da vida.

Educar para subverter a aceitação passiva do espetáculo implica a compreensão de como a totalidade das imagens interfere na formação da subjetividade social. Segundo Vermelho,

"uma das formas de intervenção subjetiva é pela sucessão rápida de imagens e de informações com que os conteúdos são veiculados pelas mídias, o que diminui bastante a possibilidade de contemplação e de reflexão e, portanto, nossa capacidade de elaboração" (Vermelho, 2002, p. 78).

Com o domínio atual da racionalidade tecnológica, a escola não está mais dando conta de suas funções de preparar para um mercado de trabalho cada vez mais exigente e excludente. No entanto, como a escola pública pode preparar os jovens para a participação ativa no mundo da cultura? Como fazer os jovens refletirem sobre seu mundo, explorando sua imaginação histórica e estética através da linguagem audiovisual?

Quando nos referimos à imaginação histórica, estamos tratando da capacidade de partir do presente e criar um conjunto de relações que interpelam a existência do passado, sua diferença ontológica, bem como suas semelhanças, reconhecendo as promessas cultivadas, porém não realizadas, no tocante a várias gerações, projetando e intervindo no fluxo do devir (Benjamin, 1994). E, quando nos referimos à imaginação estética, estamos tratando da capacidade de educar os sentidos, de alargar o mundo do sensível, da percepção humana, reconhecendo os diferentes processos de formação das subjetividades individuais e sociais, expressando diferentes formas/conteúdos de como nos relacionamos com a realidade material. Ambas devem agir pedagogicamente no sentido de abrir ao ser humano possibilidades de criar alternativas frente à realidade concreta, exercendo assim a autonomia do pensamento.

Faz-se necessário pensar novas formas/conteúdos de formação humana que tenham como referência a linguagem audiovisual, descortinando suas estruturas, bem como seu papel social (Vermelho, 2002). Além da utilização 
dos programas de TV, de filmes e vídeos como fontes para os espaços de educação escolar, explorando a construção da narrativa e desnaturalizando a realidade social existente, hoje com o aumento do acesso às câmeras digitais, às câmeras de celulares e às câmeras mini-dv, a escola e a sala de aula podem se transformar em um espaço de produção audiovisual, um espaço de socialização de um conhecimento altamente concentrado, estimulando processos de valorização humana, bem como a participação ativa no mundo da cultura. O que penso, digo e posso realizar no mundo? Poderá esta questão ser apropriada pelos jovens favelados e de periferia que freqüentam as escolas públicas?

O ponto de partida da relação entre educação e audiovisual está em transformar o processo de produção audiovisual em processo educativo. Fomentar a superação da divisão técnica do trabalho, bem como socializar o domínio das técnicas de produção audiovisual. Estimular o conhecimento do processo de produção, bem como a utilização pedagógica do produto. O conteúdo existencial e o estudo da realidade em sua dimensão histórica como fontes principais da elaboração. A interpretação da realidade que interpela, que surge de imprevisto e choca. A necessidade de expressar-se contraditoriamente em imagens, sons, versos e prosa.

A relação entre educação e produção audiovisual pode ser fomentada nas escolas públicas, como também nos projetos de extensão das universidades, na formação continuada de professores, nas escolas dos movimentos sociais. Seu desenvolvimento pelos educadores está na ordem do dia.

No entanto, para fugirmos de uma utilização ilustrativa da imagem, bem como de uma dialética da narração que reforça a identificação com a sociedade tecnológica e seu imperativo da subjetividade submissa, torna-se imprescindível ter como horizonte a produção de um conhecimento complexo, articulador das contradições existentes entre a lógica atual da produção de mercadorias e as potencialidades não só do audiovisual como instrumento da práxis pedagógica, mas do conjunto das tecnologias educacionais, o que inclui a hipermídia e educação a distância.

Portanto, o desenvolvimento da relação entre educação e produção audiovisual implica uma compreensão do conjunto de relações que demarcam a totalidade social da tecnologia no século XXI. Neste sentido, é de fundamental importância: discutir a racionalidade tecnológica numa perspectiva histórica, apresentando criticamente a naturalização do progresso tecnológico linear e seus equivalentes, progresso social e educacional; questionar a apropriação privada da terceira revolução tecnológica e científica, dos softwares e hardwares utilizados na produção de produtos audiovisuais, jogos educativos e educação a distância, tendo como base a crítica da economia política e da cultura; estimular a reflexão sobre as novas tecnologias integradas ao processo de ensino e aprendizagem na educação escolar e extra- 
escolar como ferramenta para formação de consciência histórica, preparando jovens e professores para apropriação e utilização do audiovisual como estímulo à experiência prática através de realização coletiva de vídeos, capacitando-os para a realização e edição de documentários e obras de ficção, socializando o conhecimento dos programas mais acessíveis como o Movie Maker e o Adobe Premier; apresentar o movimento software livre e sua filosofia colaborativa através da sua produção e disponibilização de softwares educativos; produzir materiais pedagógicos voltados para a educação escolar e extra-escolar, tendo como base a imagem digital, os softwares educativos e as tecnologias de aprendizagem em rede.

Estes são os pontos de partida de nossa reflexão sobre as potencialidades da produção audiovisual no contexto da educação e da sociedade brasileira contemporânea, abrindo condições para a elaboração de uma linguagem crítica pelos professores e pelos jovens das classes populares. Será, portanto, com base em experiências concretas ${ }^{7}$ que buscaremos avançar na teorização da relação educação e linguagem audiovisual, tendo como horizonte a dialética da liberdade e da autonomia humana.

\section{Notas}

1 Professora adjunta da Universidade Federal Rural do Rio de Janeiro (UFRRJ), Nova Iguaçu, Rio de Janeiro, Brasil. Doutora em Educação pela Universidade Federal Fluminense (UFF). <roberta.lobo@gmail.com>

Correspondência: Rua Cardeal Dom Sebastião Leme, 125, ap. S202, Santa Tereza, Rio de Janeiro, CEP 20240-010.

2 Faz-se necessário aprofundar o tema da automação e do tempo livre que aparece nos Grundrisse de Marx, bem como retomar o conceito de General Intellect. Ver, a propósito, Gênese e estrutura de O capital de Karl Marx, de Roman Rosdolsky (2001).

3 Os conceitos de automação progressiva e tolerância repressiva são desenvolvidos por Marcuse nas suas obras O homem unidimensional, de 1964; O fim da utopia, de 1967; Psicanálise e politica, de 1968; Idéias sobre uma teoria crítica da sociedade, de 1969; e Contrarevolução e revolução, de 1972.

4 Planeta Favela, de Mike Davis, é um primoroso estudo sobre dois séculos de reconhecimento científico da vida favelada.

5 O conceito de possibilidade possui densidade filosófica, política e epistemológica, sendo elemento essencial da práxis humana entendida como totalidade social, tal como nos ensinou Marx (1984) e Lúkacs (1981), materializando historicamente a dialética da liberdade e necessidade, finalidade e causalidade, processo-produto, valor como ser para nós e 
valor etc. Diante da projeção da consciência sobre a realidade posta abrem-se um conjunto de possibilidades para a ação humana e, dentre estas, os homens se colocam no mundo, assumem uma escolha e a sustentam.

${ }^{6}$ A compreensão e utilização do conceito de sociedade do espetáculo demarcam uma crítica aos conceitos de sociedade da informação e sociedade do conhecimento, tema a ser aprofundado em um momento futuro da linha de pesquisa Educação, Cultura e Tecnologia, do Grupo de Pesquisa Teoria Crítica e Educação da UFRRJ/CNPq.

7 Atualmente estamos atuando em várias frentes: ministrando a disciplina Tecnologia e Educação do Curso de Pedagogia da UFRRJ/Campus Nova Iguaçu; coordenando o Curso de Extensão Produção Audiovisual e Formação de Professores, voltado para 25 professores da rede municipal de educação de Mesquita; desenvolvendo junto com o Núcleo de Tecnologia Educacional da Escola Politécnica de Saúde Joaquim Venâncio/Fundação Oswaldo Cruz (Nuted/EPSJV/Fiocruz) projetos de pesquisa na área da Tecnologia Educacional numa perspectiva contra-hegemônica, em especial experiências com a linguagem audiovisual e hipermídia.

\section{Referências}

ARANTES, Paulo. Estado de Sítio. Caros Amigos Especial: Para onde vai a democracia?. São Paulo, ano VI, n. 15, nov. 2002.

BENJAMIN, Walter. Experiência e pobreza. In: BENJAMIN, Walter. Magia e técnica, arte e política. São Paulo: Brasiliense, 1994.

DAVIS, Mike. Planeta Favela. São Paulo: Boitempo, 2006.

DEPARTAMENTO INTERSINDICAL DE ESTATÍSTICA E ESTUDOS SOCIOECONÔMICOS (Dieese). Anuário dos trabalhadores. São Paulo, 2006.

\section{INSTITUTO BRASILEIRO DE GEOGRAFIA} E ESTATÍsTICA (IBGE). Censo Demográfico, Rio de Janeiro, 2000.

JAPPE, Anselm. O 'fim da arte' segundo Theodor Adorno e Guy Debord. Traduzido do espanhol por Iraci D. Poleti. Publicado em alemão em Krisis, n. 15, 1995, e em es- panhol, em Mania, n. 1, 1995. Disponível em: <http://antivalor.vilabol.uol.com.br>. Acesso em: 10 fev. 2008.

O reino da contemplação passiva. Conferência apresentada no ciclo Muito Além do Espetáculo, Teatro Maison de France, Rio de Janeiro, 9 set. 2003. Disponível em: <http://antivalor.vilabol. uol.com.br>. Acesso em: 10 fev. 2008.

LÚKACS, G. Para a ontologia do ser social: o trabalho. Tradução de Ivo Tonet (Universidade Federal de Alagoas, Ufal), de Il lavoro, cap. 1, t. 2, de Per una ontologia dell' essere sociale, Roma, Editori Riunit, 1981.

MARCUSE, Herbert. Ideologia da sociedade industrial. Rio de Janeiro: Zahar, 1967.

Liberdade e agressão na sociedade tecnológica. In: Revista Civilização Brasileira, n. 18, ano III, março-abril, 1968. 
MARX, Karl. A ideologia alemã e teses sobre Feuerbach. São Paulo: Centauro, 1984.

MENEGAT, Marildo. O olho da barbárie. A guerra civil no Brasil. São Paulo: Expressão Popular, 2006.

ROSDOLSKY, Roman. Gênese e estrutura de O capital de Karl Marx. Rio de Janeiro: Contraponto, 2001.
VERMELHO, Sandra. Algumas reflexões em torno da tecnologia como expressão da subjetividade. In: LEITE, Márcia; FILÉ, Valter. (Orgs.). Subjetividades, tecnologias e escolas. Rio de Janeiro: DP\&A, 2002.

WAISELFISZ, Júlio Jacob. Mapa da violência nos municípios brasileiros. Brasília: Organização dos Estados Ibero-americanos para Educação, Ciência e Cultura, 2007.

Recebido em 10/01/2008

Aprovado em 26/02/2008 